\title{
O FIO E A MISSANGA: PENSANDO A FORMAÇÃO DOCENTE A PARTIR DE NARRATIVAS DA EXPERIÊNCIA NA ALFABETIZAÇÃO DE JOVENS E ADULTOS
}

\author{
DANIEL DE OLIVEIRA ${ }^{1 ; 2}$ \\ ORCID: https://orcid.org/0000-0001-7631-213X \\ MAIRCE ARAUJO ${ }^{2}$ \\ ORCID: https://orcid.org/0000-0003-1434-7796
}

\begin{abstract}
RESUMO: O presente artigo problematiza uma forma de compreensão da formação docente, que se dá nos atravessamentos cotidianos a partir de experiências (LARROSA) mobilizadas pelo exercício da docência. Metodologicamente optamos pela pesquisa narrativa e (auto)biográfica, na medida em que esse caminho nos possibilita falar com a escola e a partir da escola, ao invés de falar sobre a escola. O objetivo desse artigo é produzir reflexões que contribuam para o debate sobre essa perspectiva de formação que compreende a experiência como lócus privilegiado da formação docente e a narrativa docente como meio de refletir sobre o vivido na docência, o que nos permitiu compreender como o olhar do outro ajuda a nos formar. Trazemos aqui a narrativa de um processo de aprendizagem da leitura e da escrita, em uma turma de alfabetização da Educação de Jovens e Adultos (EJA), no município do Rio de Janeiro, envolvendo a produção de uma carta, no qual uma estudante e seu professor vivem a experiência do ensinaraprender como acontecimento (GERALDI), colocando questões sobre a teoriaprática alfabetizadora em curso nos cotidianos escolares. Ajudam na reflexão sobre o tema Freire (1996, 2014), Garcia e Alves (2002; 2012), Larrosa (2014) e Geraldi (2015). Na experiência aqui narrada, a relação dialógica entre uma estudante e seu professor, ao longo das aulas, nos permitiu perceber o que esses diálogos vividos revelavam sobre o processo de aprendizagem dessa estudante, ao mesmo tempo em que se constituiu também formativo para o professor.
\end{abstract}

Palavras-chave: Formação docente continuada, Educação de Jovens e Adultos, Alfabetização.

\section{THE THREAD AND THE BEAD: THINKING ABOUT TEACHER EDUCATION FROM NARRATIVES OF THE EXPERIENCE IN YOUTH AND ADULT LITERACY}

\begin{abstract}
This paper discusses a way of understanding the teacher education, which takes place in everyday crossings from experiences (LARROSA) mobilized by the exercise of teaching. Methodologically, we opted for narrative and (auto)biographical research, as this path allows us to talk to the school and from the school, instead of talking about the school. The purpose of this article is to produce reflections that contribute to the debate about this perspective of training that understands the

\footnotetext{
${ }^{1}$ Secretaria Municipal de Educação do Rio de Janeiro/ Gerência de Educação de Jovens e Adultos; (SME-RJ/ GEJA). Rio de Janeiro, RJ, Brasil. <profoliveira.d@gmail.com>

${ }^{2}$ Universidade do Estado do Rio de Janeiro/ Faculdade de Formação de Professores (UERJ/ FFP). Rio de Janeiro, RJ, Brasil. <mairce@hormail.com>
} 
experience as a privileged locus of teacher training and the teacher narrative as a means of reflecting on the teaching experience, which allowed us to understand how the other's view helps to form us. We bring here the narrative of a learning process of reading and writing in a literacy class of the Adult and Young Adult Education (EJA), in the city of Rio de Janeiro, involving the production of a letter, in which a student and her teacher live the experience of teaching-learning as an event (GERALDI), posing questions about the literacy theory-practice in course in everyday school. Freire (1996, 2014), Garcia and Alves (2002; 2012), Larrosa (2014) and Geraldi (2015) help in the reflection on the subject. In the experience narrated here, the dialogical relationship between a student and her teacher, throughout the classes, allowed us to realize what these dialogues revealed about the student's learning process, while it was also formative for the teacher.

Keywords: Continuing teacher education, Youth and Adult Education, Literacy.

\section{EL HILO Y LAS CUENTAS: PENSANDO LA FORMACIÓN DOCENTE DE NARRATIVAS DE EXPERIENCIA EN LA ALFABETIZACIÓN DE JÓVENES Y ADULTOS}

RESÚMEN: El presente artículo problematiza una forma de entender la formación docente, que se produce en los cruces diarios de experiencias (LARROSA) movilizados por el ejercicio de la enseñanza. Metodológicamente, optamos por la investigación narrativa y (auto)biográfica. Este camino nos permite hablar con la escuela y desde la escuela, y no sobre la escuela. El objetivo de este artículo es producir reflexiones que contribuyan al debate sobre esta perspectiva de la educación que incluye la experiencia como un lugar privilegiado de la formación del profesorado y la narrativa docente como un medio para reflexionar sobre lo que se vivió en la enseñanza, lo que nos permitió comprender cómo otro nos ayuda a formarnos. Traemos aquí la narrativa de un proceso de aprender a leer y escribir, en una clase de alfabetización de Educación de Jóvenes y Adultos (EJA), en la ciudad de Río de Janeiro, que implica la producción de una carta, en la que una estudiante y su maestro vive la experiencia de enseñar a aprender como un evento (GERALDI), haciendo preguntas sobre la teoría de la alfabetización en curso en la rutina escolar. Ayudan a reflexionar sobre el tema Freire (1996, 2014), García y Alves (2002; 2012), Larrosa (2014) y Geraldi (2015). En la experiencia narrada aquí, la relación dialógica entre una estudiante y su maestro, a lo largo de las clases, nos permitió comprender lo que estos diálogos vividos revelaron sobre el proceso de aprendizaje de la estudiante, al mismo tiempo que también era formativo para el maestro.

Palabras clave: Formación docente continua, Educación de jóvenes y adultos, Alfabetización. 


\section{INTRODUÇÃO}

A missanga, todas as vêem.
Ninguém nota o fio que,
Em colar vistoso, vai compondo as missangas.
Também assim é a voz do poeta:
Um fio de silêncio costurando o tempo

(MIA COUTO, 2009).

Abrimos o artigo com uma epígrafe de Mia Couto (2009), escritor moçambicano, que compara a voz do poeta ao "invisível” fio indispensável à composição de um colar, porém quase nunca notado em relação às missangas vistosas que saltam aos olhos. "A missanga, todas as vêem. Ninguém nota o fio que, em colar vistoso, vai compondo as missangas" (COUTO, 2009). Ambos, fio e missangas, são importantes para o colar, porém é o fio que vai unindo cada uma delas.

Pedimos licença para fazermos uma analogia que nos parece razoavelmente adequada: as experiências de vidaformação ${ }^{3}{ }^{4}$ narradas pelos/as docentes nas salas de professores, nos cursos de formação continuada, nas trajetórias de ida e vinda de casa para o trabalho, nos momentos de lazer em que se encontram... não poderiam ser comparadas ao fio do colar, de que nos fala Mia Couto?

O tema da formação docente no cotidiano da escola tem se constituído, para nós, um constante desafio teóricoprático, que nos leva a tensionar e complexificar os modos hegemônicos de pensar e propor ações e projetos de formação inicial e continuada. Concentrando nossas investigações na escola básica e elegendo-a como centralidade nos processos formativos (CANÁRIO, 2005) temos nos esforçado para contribuir com a construção de paradigmas emergentes de formação, que possam romper com racionalidades tecnicistas e aplicativas, que persistem em reservar para os/as docentes o lugar de consumidores de métodos e práticas de ensino formulados ao largo da escola.

Tais perspectivas têm nos levado ao encontro das narrativas docentes, tanto como processo de formação docente, quanto como processos investigativos. Lembramos que o uso das narrativas como método de investigação ou de pesquisa, começaram a surgir de uma forma mais contundente no Brasil, nos últimos trinta anos, a partir das contribuições de Nóvoa (1991, 1992), com as histórias de vida de professores/as, seguido por Clandinin e Connelly (2015), entre outros.

Em comum entre os/as pesquisadores/as que se alinhavam com a visão narrativa ou (auto)biográfica estava o desconforto com produções no campo da educação, que "olhando a escola do alto" (ALVES, 2001), ou a partir do que a escola não é ou faz, se caracterizaram por falar sobre a escola e as práticas docentes, em vez de falar com ela e a partir dela. Em contraponto a esse olhar distante, enviesado que aparece quando a escola e seus sujeitos são tratados apenas como objeto de pesquisa, os resultados que começam a surgir a partir da investigação narrativa vão confirmando que são diferentes os modos de compreensão e significação sobre a prática e os acontecimento cotidianos quando os sentidos são elaborados pelos próprios sujeitos pesquisados (GERALDI, 2006).

Como afirmam Lima, Geraldi e Geraldi (2015, p.19), "genuinamente diferentes são os sentidos produzidos pelas pesquisas em que os próprios sujeitos são autores e coautores das narrativas. Em outras palavras, pesquisar sobre os professores e pesquisar com os professores ou pesquisar na escola e com a escola, resultam em estudos diversos".

3 Em diálogo com outros grupos de pesquisa, em especial, o Grupo Polifonia, (Vozes da Educação, FFP/UERJ/FE/UNICAMP), coordenado pela Prof ${ }^{a}$ Dr Ines Bragança e o Grupo de Estudos e Pesquisas em Educação Continuada (GEPEC), coordenado pelo Prof. Dr Guilherme Prado (FE/UNICAMP) vimos discutindo a noção de pesquisaformação como modo de viver, pesquisar, narrar e formar que emerge na interface entre as pesquisas narrativas (auto)biográficas em educação, as pesquisas nosdoscom os cotidianos escolares e as concepções-ações de formação humana que se fazem (BRAGANÇA, 2018).

${ }^{4}$ O registro do termo vidaformação escrito junto e em itálico, segue o que nos ensinam Garcia e Alves (2012) quando assumimos que buscamos superar a dicotomia causada entre esses termos, assim como ao tratar o pensar e o fazer docente. Essa opção, segundo as autoras, se expressa na escrita procurando estabelecer uma coerência entre conteúdo e forma. Em nossos textos, utilizamos também essa mesma referência em palavras como teóricoprático, teoriaprática, ensinaraprender, pensarfazer, entre outras, sempre com a mesma finalidade. 
Em nossa trajetória de pesquisa, vimos desenvolvendo diferentes ações investigativasformativas, buscando constituir espaços de memória, de narração e de (auto)formação, tanto na universidade quanto no interior das escolas, pensando a reflexão sobre a prática pedagógica como um elemento estruturante de formação docente. Temos na abordagem (auto)biográfica uma das referências inspiradoras de caminhos teórico-metodológicos que entrelaçam os processos de investigação e de formação.

As narrativas têm ocupado lugar muito importante no processo formativo docente porque vão revelando as nossas experiências, os nossos referenciais teóricos-epistemológicos, nossos percursos formativos e os nossos lugares de fala. A partir delas, somos provocados/as a pensar nossas práticas e nossa formação; somos convidados a problematizá-las em inúmeros aspectos. Assim como as missangas, a prática em si, a parte mais visível do nosso fazer pedagógico, não seria atravessada por um fio de experiências invisíveis, que transbordam nas narrativas e são criadores da pré-disposição para nos ouvirmos e investigarmos a própria prática?

Como o fio que compõe o colar das missangas, as narrativas docentes orais ou escritas que temos encontrado em nossas investigações, provocadas pelo exercício exotópico, ressignificam práticas e experiências pedagógicas, contribuindo para desvelar formas outras de pensarpraticar os saberesfazeres docentes, produzir e socializar esses conhecimentos.

Temos, portanto, em nossas ações e pesquisas, defendido a escola e o cotidiano escolar como espaço de formação. Isto implica compreender o/a professor/a como pesquisador/a de sua prática, entendendo que essa atitude pode favorecer a construção de práticas educativas mais favoráveis aos estudantes. Como nos ensinava Freire (1996, p. 44) "é pensando criticamente a prática de hoje ou de ontem que se pode melhorar a próxima prática", pois quanto mais a professora analisa e percebe as razões que fundamentam a sua prática, mais se torna capaz de mudar ou mover-se, "do estado da curiosidade ingênua para o da curiosidade epistemológica"" (FREIRE, 1996, p. 44). "Temos visto o/a professor/a que reconhece a investigação de sua própria prática como um importante instrumento de ação, contribuindo, nos espaços coletivos de formação, com outros/as professores/as, narrando suas experiências, compartilhando suas inquietações e socializando seus avanços" (MORAIS e ARAÚJO, 2014, p. 32).

Discutindo a potencialidade da narrativa para a compreensão e ressignificação dos fazeres ordinários que emergem no cotidiano escolar, compreendemos que o fio que costura as narrativas dos/as professores/as compõem-se de múltiplas experiências vividas no chão da escola e das comunidades que cercam a escola, experiências que se encontram nas inquietudes suscitadas no e pelo cotidiano, que mobilizam a reflexão sobre a prática. A participação em coletivos docentes que assumem uma postura investigativa a partir do cotidiano da escola e da comunidade e o enfrentamento ao desafio de transformar narrativas orais, prática mais tradicional entre docentes, em narrativas escritas são outros fios a costurar as narrativas aqui contempladas.

A escrita das narrativas por professores/as se inscreve, assim, como um esforço e como luta para dizer a própria palavra, seus saberes e dizer sobre si, como um exercício de autoria. Parte da discussão teórica deste texto, recorte de uma dissertação de mestrado de um dos autores, se inscreve nesse exercício de autoria, problematizando o fio que compõe as missangas.

Perceber as contribuições das narrativas docentes, orais ou escritas, como um efeito em rede, que provoca outros/as professores/as a também pensarem sobre seus referenciais, preferências, metodologias, sucessos e fracassos pode ser apontado como uma primeira apreensão da interlocução entre as experiências trazidas pelo presente artigo.

Refletir sobre a própria prática docente não é um ato que precise ser solitário. Por acreditar em tal perspectiva, em nossas ações investigativo-formativas temos priorizado uma metodologia que favorece as trocas entre pares, compartilhando práticas, histórias, experiências, olhando juntos, refletindo, pensando e estudando juntos, procurando caminhos para uma prática alfabetizadora mais comprometida com o sucesso de crianças, jovens e adultos das classes populares. "As memórias das professoras povoam

\footnotetext{
${ }^{5}$ Para Paulo Freire (1996), a construção do conhecimento implica o exercício da curiosidade que pode transitar da ingenuidade para a curiosidade epistemológica. A curiosidade ingênua produz o saber da experiência feito. Por meio de procedimentos metodicamente rigorosos, esse saber da experiência feito vai se criticizando, tornando-se curiosidade epistemológica.

Educação em Revista|Belo Horizonte|v.37|e21958|2021
} 
suas práticas, às vezes de forma errante, sem grandes reflexões, assumidas após análises solitárias ou de grupo. Trabalhadas como memórias coletivas, irão produzir um texto que possibilitará a compreensão de práticas assumidas no cotidiano" (PARK, 2003, p 36).

Entendemos, assim, os coletivos docentes como espaços de interlocução entre pares, em que docentes dividem ou melhor dizendo, compartilham suas perguntas, desafios, angústias, experiências e saberes docentes; narram, estudam, aprendem a pesquisar e escrevem sobre a própria prática docente. No Estado do Rio de Janeiro, nas universidades e na escola básica, destacamos grupos e coletivos docentes $^{6}$, bem como suas produções intelectuais, que têm se configurado como fecundos espaços formativos imprescindíveis na construção dos referenciais com os quais dialogamos hoje sobre coletivos docentes, professor/a-pesquisador/a, narrativas de professores/as, pesquisa (auto)biográfica, experiência, memória, alfabetização.

A necessidade de se reunir em um coletivo é algo que, podemos arriscar dizer, é inerente ao ser humano. Entre alguns professores a necessidade de se reunir a um coletivo foi sentida por muitas vezes, segundo seus próprios relatos, para conseguir pensar juntos em como resolver questões pedagógicas que diariamente emergem do cotidiano nas salas de aula de nossas escolas.

Nessa perspectiva do fazer juntos, escrevemos esse artigo e refletimos juntos, a partir da experiência vivida por um de nós na escola e das provocações que tal experiência provocou em nós.

\section{UM FLASH DO COTIDIANO: INTERROGANDO O VIVIDO}

Nos onze anos atuando em uma Rede Pública Municipal de ensino, oito desses anos foram vividos atuando na Educação de Jovens e Adultos (EJA), no Ensino Fundamental, entre a sala de aula como professor alfabetizador, orientação e coordenação pedagógica. Em um desses anos, atuando na Educação de Jovens e Adultos como professor alfabetizador de uma turma inicial de alfabetização, uma aluna, Antônia ${ }^{7}$, - uma mulher, nordestina, negra, das camadas populares, que já passava dos setenta anos - com muita seriedade na voz, olhando em meus olhos, disse que eu precisava lhe ensinar a escrever uma carta. Ela me disse que não queria aprender mais nada da escola, naquele momento. O mais importante era aprender a escrever uma carta para um irmão que morava distante, em outro estado do Brasil.

A turma de alfabetização de jovens e adultos da qual Antônia fazia parte era majoritariamente feminina, majoritariamente formada por adultos (com alguns jovens e alguns idosos), majoritariamente de nordestinos ou descendentes de nordestinos, todos pertencentes à classe trabalhadora, moradores de comunidades (ou residentes próximos a elas). Como foi possível constatar ao assumir a turma, analfabetos ou, com pouquíssimas exceções, iniciando processos de leitura e escrita convencionais.

Ao longo das primeiras aulas, Antônia insistiu que escrever uma carta para o irmão era tudo que lhe interessava na escola. Embora se envolvesse com os temas discutidos em classe e se dedicasse às atividades com boa vontade e, algumas vezes, até entusiamada, Antônia voltava sempre para a mesma tecla: queria aprender a escrever a sua carta. Tudo o mais poderia ficar depois. Escrever a carta era o seu objetivo e a razão maior para estar na escola. Ela tinha pressa, talvez pelo fato da idade já avançada e de alguns problemas de saúde, que ela declarava dificultarem e impedirem sua presença nas aulas.

Meu planejamento, a partir das Orientações Curriculares para a Educação de Jovens e Adultos $^{8}$, era traçado em duas perspectivas: uma de longo prazo, que apontava os objetivos e linhas gerais de ação do trimestre (o ano letivo da EJA nessa rede divide-se em trimestres); outra de curto prazo, semanal, no qual as questões emergidas do cotidiano se articulavam aos objetivos trimestrais. No dia a dia, preocupava-me em ouvir as vozes dos estudantes em busca de dar sentido ao currículo.

\footnotetext{
${ }^{6}$ Nossa referencia aqui diz respeito aos grupos e coletivos docentes dos quais temos participado ao longo de nossa própria trajetória docente, que nasceram dentros das escolas ou da universidade a partir do movimento dos/das docentes, especialmente: Rede de coletivos Docentes que Estudam e narram sobre Alfabetização, Leitura e Escrita - REDEALE/FFPUERJ; e Grupo de Estudos e Formação de Escritores e Leitores - GEFEL/ISERJ. Para maiores informações ver: Morais e Araujo (2018), sobre a REDEALE, ou Santos et al (2013), sobre o GEFEL.

${ }^{7}$ Antonia é um nome fictício substituindo o verdadeiro em preservação à identidade da estudante. Do mesmo modo, não precisar a identidade da escola ou época dessa experiência faz parte dessa preservação de sua identidade.

${ }^{8}$ Essa rede de ensino possuí um currículo específico para a Educação de Jovens e Adultos em nível de Ensino Fundamental. Educação em Revista|Belo Horizonte|v.37|e21958|2021
} 
Contudo, a solicitação de Antônia me deslocou. Exigia de mim romper com a lógica que orientava meu planejamento e entrar no fluxo do que Geraldi (2015) nomeia como a "aula como acontecimento". Discutindo sobre uma nova identidade docente, para o/a professor/a do futuro, o pesquisador nos alerta que o papel do/da docente hoje é " do sujeito capaz de considerar o seu vivido, de olhar para o seu aluno como um sujeito que também já tem um vivido, para transformar o vivido em perguntas" (GERALDI, 2015, p.95). Mais adiante, o autor complementa: "é somente quem aprende percorrer caminhos inexistentes, porque eles se fazem no percurso, será capaz de compreender as respostas e os caminhos antes percorridos" (GERALDI, 2015, p.96).

Antônia me desafiava a percorrer caminhos inexistentes. Assim, começamos a escrever a tal carta. Combinamos que a cada semana trabalharíamos na carta. Porém, Antônia não era a única aluna da turma, os/as demais estudantes também possuíam suas demandas, tinham outros desejos e objetivos diferentes para estar na sala de aula. Para alguns/as desses/as estudantes a escrita de cartas não era uma atividade relevante naquele momento. Talvez por não terem um destinatário concreto, como fora o caso de Antônia. Lidar com a heterogeneidade em sala de aula é sempre um desafio. Mas já havia aprendido em minha trajetória a não envolver a turma inteira com uma mesma atividade. As aulas aconteciam a partir de temas de discussão que propúnhamos, ora eu, ora a turma, liamos textos variados, assim como desenvolvíamos propostas de escritas diversas etc. Durante o período letivo fomos experimentando a escrita de diferentes gêneros textuais, contudo, para Antônia a principal proposta de produção escrita era a carta que queria escrever para o seu irmão.

Antônia reunia as condições essenciais para que a escrita acontecesse: tinha um destinatário concreto, um motivo real a ser comunicado, uma relação afetiva entre ela e seu interlocutor. Dialogando com Smolka (2012), poderíamos dizer que a estudante, mesmo sem "o domínio das letras", estava em condições de produzir sua escrita, pois guiava-se pelas questões chave mobilizadoras da produção escrita que conserva o sentido e o significado social da língua escrita: escrever o que? para quem? e para que?

Smolka (2012), no livro "A criança na fase inicial da escrita - Alfabetização como processo discursivo", defende que ensinar ou aprender a ler e a escrever são ações complexas que se processam no jogo das representações sociais e das trocas simbólicas. Tendo como interlocutores centrais as teorias de Vygotsky e Mikhail Bakthin, a autora tomando como base o aspecto fundamentalmente social e interlocutivo das condições e do funcionamento da escrita aponta que: “"não se ensina ou se aprende” simplesmente a 'ler' e a 'escrever'. Aprende-se (a usar) uma forma de linguagem, uma forma de interação verbal, uma atividade, um trabalho simbólico" (SMOLKA, 2012, p.60).

Pouco a pouco ela escrevia a sua palavra, tratávamos juntos forma e conteúdo da carta; às vezes, ela permitia que seu texto fosse apreciado coletivamente como proposta de revisão. A revisão textual como parte do processo de aprendizagem da escrita era uma atividade de rotina em classe e era realizada de três formas: às vezes, individualmente, pelo próprio autor, outras vezes, na troca dos textos entre duplas, e coletivamente, com a turma inteira, a partir dos textos reproduzidos no quadro negro.

Em minhas ações cotidianas, buscava atender as recomendações de Geraldi (2015):

o professor somente ensina a escrever se assume os processos de escrever do aluno, tornandose dele um co-enunciador, um leitor privilegiado e atento, um coloraborador capaz de encorajar o outro a continuar buscando a melhor forma de dizer o que quer dizer para quem está dizendo pelas razões que o levam a dizer o que diz (GERALDI, 2015, p.98).

Esse era um dos princípios que subsidiavam minha prática. Contudo, possivelmente, ecos de uma formação que ainda mora em nós e acredita reservar ao docente o poder de determinar o que o/a aluno/a sabe ou não sabe, em minha avaliação a carta de Antônia estava praticamente pronta, porém com algumas correções a fazer.

Num determinado dia, a estudante me apresentou sua carta ao final da aula. Estava eufórica. Sentia-se muito feliz por constatar que estava aprendendo a escrever, a ler e, principalmente escrever sua carta. Após ler a carta que Antônia me apresentava, também fiquei feliz e a parabenizei. A carta estava bem escrita, havia poucas coisas a revisar e, no lugar do professor que acredita saber mais sobre o processo de aprendizagem do que o próprio aprendiz, propus a revisão para a aula seguinte.

Muito segura de si, Antônia recusou a proposta. Disse-me que sua carta não necessitava de novas correções. Qualquer nova correção apagaria sua identidade naquela carta. Com suas palavras, 
Antônia defendia que o texto poderia ficar mais correto do ponto de vista das normas da língua, talvez, até mais poético, mas, já não seria o seu texto.

O primeiro impulso que tive foi de questioná-la e tentar convencê-la da importância de fazer a revisão, mas não o fiz; também eu já havia me visto naquela situação... Apenas consegui dizer um "tudo bem". As palavras de Antônia foram do tipo que, não sabemos bem como, nos arrebatam para um outro "lugar": como eu me senti nas intervenções feitas em textos escritos entre pares, na escrita acadêmica e, antes, na escola básica? Eu fui para casa pensando. Estava aprendendo que a avaliação não é feita somente da perspectiva do professor e passei a propor as avaliações de forma participativa com os estudantes, ouvindo o que percebiam sobre seus processos de aprendizagem e como avaliavam as produções desenvolvidas.

$\mathrm{Na}$ noite seguinte, trabalhamos em sala de aula como endereçar o envelope para enviar a carta. $\mathrm{Na}$ aula posterior, Antônia comunicou que já havia postado a carta nos correios. Dias depois, compartilhou com a turma a felicidade de ter recebido um telefonema do irmão comentando sobre a carta, respondendo as perguntas que ela havia endereçado e a alegria dele por constatar que agora Antônia aprendera a ler e a escrever. Muito mais do que aprender a escrever uma carta, Antônia aprendeu e me ensinou que ler e escrever é se apropriar de uma "forma de dizer o que quer dizer para quem está dizendo pelas razões que o levam a dizer o que diz" (GERALDI, 2015, p. 96).

Antônia, certa vez, contou-me sua história, revelando o motivo de não ter aprendido a ler e a escrever quando ainda era criança. Seu pai não queria que ela aprendesse a escrever, para que não escrevesse para namorado. Ela nem tinha um namorado, mas seu pai dizia que agia assim para lhe vigiar e ter certeza de que ela só namoraria no "tempo certo e com a pessoa certa", que, naturalmente, seria escolhida por ele. Antônia não foi para a escola, mas foi para o trabalho na roça.

A história de Antônia, a história de uma mulher negra comum, como tantas outras, nos conta a história de uma sociedade patriarcal, racista, cujo papel histórico reservado às mulheres é o da submissão. Antônia tem setenta anos, portanto, nasceu na década de 1950, quando a Lei àurea, que acabou oficialmente com a escravidão no país, já completara cento e setenta e dois anos. Mesmo assim, como mulher negra e pobre Antônia continua(va) escravizada, na medida em que foi interditada em seu direito de acesso à escolaridade e ao conhecimento produzido historicamente. Por outro lado, a ausência da escolaridade também acaba por determinar o tipo de trabalho que lhe será reservado - trabalhar na roça, como empregada doméstica, como babá, como faxineira etc.

Apple (2017) discute a necessidade de a Educação "agir contra a ideologia, os processos e as práticas institucionais que reproduzem condições opressivas" (APPLE, 2017, p. 901); a isso chama de processo de reposicionamento, no qual devemos procurar "enxergar o mundo pelos olhos dos despossuídos" (APPLE, 2017, p.901). De que adiantaria manter o planejamento inicial, se ele não pudesse garantir, por exemplo, à Antônia que ela tivesse acesso a um conhecimento que lhe era tão significativo e que permitiria se aproximar de sua família, se comunicando pela carta? E assim com os demais, cada qual com aquilo que the era mais caro. De que adiantaria fazer ao rigor o planejamento inicial e, com isso, reproduzir condições curriculares opressivas? Foi fundamental thes restituir aquilo que, de maneira ou outra, fora negado anteriormente e que os colocara em situação de restrição de condições visto estarmos em uma sociedade grafocêntrica, onde as condições de leitura e escrita podem ser convertidas em relações de poder.

Apple (2017) acrescenta que para romper com as relações institucionais reprodutoras das condições opressivas, constituindo com o "reposicionamento" as bases da pedagogia crítica,

devemos pensar em termos de relações. Isto é, entender que a educação exige que a enxerguemos, na sua essência, como ato político e ético. Isto quer dizer que precisamos situá-la novamente nos contextos de relações desiguais de poder, na sociedade em geral e nas relações de exploração, domínio e subordinação, e -nos conflitos- que são gerados por essas relações (APPLE, 2004 apud APPLE, 2017, p. 901).

O diálogo que desenvolvemos, Antônia e eu, permitiu conhecer o seu maior desejo de aprender e sua maior necessidade naquele momento. Permitiu também conhecer a sua história e negociarmos sentidos para um currículo, repensar um planejamento, negociar os sentidos de uma avaliação. 
Em uma perspectiva de educação dialógica (FREIRE, 2014), a palavra não é privilégio de alguns, mas direito de todos; a Educação se faz no diálogo entre os sujeitos. Isso abre espaço, por exemplo, para discutir em aula o que será estudado, quando e como será estudado e como será avaliado, remetendo ao currículo, planejamento e avaliação. Nessa experiência que trago para o texto, a palavra da estudante é direito e transformam a prática no que diz respeito ao seu planejamento e avaliação; primeiro, como palavra falada que argumenta negociando um sentido para sua produção e, depois, como palavra escrita sobre a qual negociamos os sentidos da revisão textual.

Ao tratar o diálogo como fenômeno humano, Freire (2014, p.107), afirma "não há palavra verdadeira que não seja práxis. Daí que dizer a palavra verdadeira seja transformar o mundo". A práxis resulta de um processo de ação-reflexão, uma relação dialógica, tendo em Freire o entendimento da indissociabilidade desses dois elementos, posto que a dicotomia entre eles poderia se reduzir à ação pela ação ou à palavra vazia.

O destaque sobre a dimensão da reflexão na prática docente, principalmente na educação básica, tem no Brasil dois representantes cujo pensamentos influenciaram e ainda influênciam muitos professores/as: Paulo Freire e Regina Leite Garcia. A produção desses pensadores contribuiu de forma significativa para a transformação das concepções educacionais e dos fazeres de muitos educadores. A concepção professora-pesquisadora, no Brasil, foi amplamente discutida por Regina Leite Garcia, que também fortaleceu a discussão sobre a relação práticateoriaprática.

Garcia e Alves (2002, p.110) afirmam que "a prática pedagógica é um espaço de teoria em movimento". Com isso, ela está explicando a professora-pesquisadora, sua existência, a sua necessidade. A prática com espaço de teoria em movimento propõe reconhecer, compreender, afirmar esses três elementos - prática, espaço (do cotidiano) e teoria - como não definitivos, maleáveis e heterogêneos. Ou seja, considerando que o cotidiano se transforma pela presença de sujeitos diferentes e suas formas de ser e estar no mundo, das práticas no cotidiano escolar são demandadas que atendam a uma diversidade de pensar e de formas de aprender e que, nesse sentido, pressupõe sempre um novo olhar, um novo problematizar, um novo criar, lidar com nossas dúvidas, a partir da reflexão que produz novos conhecimentos e teorias.

É nesse sentido que Garcia e Alves (2012) discutem a relação práticateoriaprática que para as autoras significa-se como a interdependência dialógica entre prática e teoria; mais que isso a indissociabilidade entre elas. O entrelaçar de duas dimensões em que a prática se articula à teoria por meio de processos reflexivos.

[...] fomos compreendendo ser a prática, a teoria em movimento e a teoria, o resultado da reflexão sobre a prática. Ou seja, fomos descobrindo não haver prática despida de teoria tampouco teoria que não resulte da prática. [...] na prática que é confirmada a teoria, e quando não, é na prática que a teoria é atualizada ou mesmo modificada, quando não dá conta de explicar o que acontece na prática (GARCIA e ALVES, 2012, p. 491).

Uma prática que está repleta de teoria porque ela produz conhecimento ao mesmo tempo relacionando-se dialogicamente com nossos referenciais com os quais nos identificamos ao longo da vida, mesmo que não esteja explícito.

O processo reflexivo do professor-pesquisador, da Práxis, tanto para Freire (2014), quanto para Garcia (2011) possui um elemento em comum: a consciência da incompletude de cada um de nós. Para Freire (2014),

Mais uma vez os homens desafiados pela dramaticidade da hora atual, se propõe a si mesmos como problema. Descobrem o pouco que sabem sobre si, de seu "posto no cosmos", e se inquietam por saber mais. Estará, aliás, no reconhecimento do seu pouco saber de si uma das razões desta procura. Ao se instalarem na quase, senão trágica, descoberta do seu pouco saber de si, se fazem problema a eles mesmos. Indagam. Respondem, e suas respostas os levam a novas perguntas (FREIRE, 2014, p. 39).

Nas palavras de Garcia (2011, p. 20), "Hoje sabemos que a dúvida, a incerteza, a insegurança, a consciência de nosso ainda não saber é que nos convida a investigar e, investigando, podermos aprender algo que antes não sabíamos". O reconhecimento de nossa incompletude e da necessidade de 
encontrarmos respostas para os desafios que nos são propostos cotidianamente nos move a pesquisar na docência.

Para ela, a professora inconformada com os discursos sobre o fracasso escolar, que culpabilizam os próprios estudantes, e comprometida com o sucesso dos mesmos e em busca de respostas assume uma postura investigativa (GARCIA; ALVES, 2002). E eu, diante da mesma situação, de não me conformar com as explicações que não explicam, muito comuns de serem ouvidas, do tipo "falta apoio da família", "os irmãos também foram assim", "falta interesse dele", "deve ser um problema de fono (fonoaudióloga) ou algum bloqueio psicológico"..., também adotei uma postura de investigação. Esse tipo de respostas de forma simplista culpabilizam o sujeito, rotulam e não ajudam a lidar com as questões dos processos de ensinoaprendizagem que nos desafiam cotidianamente. Assumi uma atitude investigativa para compreender alguns dos desafios que minha prática docente enfrentava com relação esses processos, para compreender a minha prática, como reagem ao seu estímulo os estudantes, o impacto dela nas relações dos estudantes com o conhecimento.

Ao me permitir fundamentar minha prática nos princípios da ação-reflexão ou da relação práticateoriaprática, ou seja, uma práxis docente, acredito que o ponto mais importante dessa minha experiência não foi trazer a carta para a sala de aula, pensar a forma de organizar um trabalho com a carta e atender às expectativas de uma estudante e dos outros estudantes. O momento com o qual mais aprendi foi avaliar juntos - professor e estudante. Ao propor mais uma revisão à estudante, ela assume que seu texto não pode ser mais mexido, que ele já a satisfez, que há uma relação de identidade na sua forma de escrever que o marca e não quer que se apague.

\section{CONSIDERAÇÕES FINAIS}

Retomando aqui o diálogo sobre a metodologia de pesquisa que subsidia nossas reflexões trazemos novamente Geraldi, Geraldi e Lima (2015), quando apontam que a especificidade de investigações que fazem uso de narrativas de experiências educativas,

reside no fato de que o sujeito da experiência a narra para, debruçando-se sobre o próprio vivido e narrado, extrair lições que valham como conhecimentos produzidos a posteriori, resultando do embate entre a experiência e os estudos teóricos realizados após a experiência narrada. A pesquisa que pode ser deflagrada a partir da narrativa da experiência não é uma construção anterior à experiência. É da experiência vivida que emergem temas e perguntas a partir dos quais se elegem os referenciais teóricos com os quais se irá dialogar e que, por sua vez, fazem emergir as lições a serem tiradas [...] (Geraldi, Geraldi e Lima, 2015, p. 27).

Nesse sentido, debruçando-nos sobre a experiência narrada, sintetizamos algumas lições ou conhecimentos produzidos que o vivido trouxe para nós. Com a turma e, especialmente, com as provocações e determinações de Antonia, aprendemos sobre o currículo, avaliação e planejamento, instigando-nos a pensar sobre o desafio de articular as dimensões individuais e coletivas, considerando objetivos diferentes, pontos de partida diferentes e "pontos de chegada" diferentes.

Temas e perguntas também foram suscitados pela reflexão sobre a experiência. A relação dialógica é um processo de aprendizagem sempre em construção. Nessa relação dialógica docenteestudante na Educação de Jovens e Adultos, quantas coisas se revelam sobre o que sabem os/as educandos/as em suas vastas experiências de vida? Que contribuições os sentidos que negociam no cotidiano trazem para os saberesfazeres que circulam na escola? Há espaço para essas proposições e negociações? Que pistas nos oferecem sobre seus processos de aprendizagem? Como garantir no cotidiano possibilidades de participação desses sujeitos na decisão sobre o que querem aprender, sobre os sentidos negociados para a aprendizagem e sobre a significação da (auto)avaliação dos seus processos de aprendizagens? Acreditamos que as respostas para tais perguntas suscitam nos colocarmos no lugar exotópico, do qual nos fala Bakhtin (1992). Diz o autor sobre exotopia:

Devo identificar-me com o outro e ver o mundo através de seu sistema de valores, tal como ele o vê; devo colocar-me em seu lugar, e depois, de volta ao meu lugar, completar seu horizonte com tudo o que se descobre do lugar que ocupo, fora dele; devo emoldurá-lo, criar-lhe um ambiente que o acabe, mediante o excedente de minha visão, de meu saber, de meu desejo e de meu sentimento (BAKHTIN, 1992, p.45). 
É nesse sentido de ouvir a voz do outro, que nos revela coisas a seu respeito que de outro modo não poderíamos saber, que entendemos as vozes dos/das estudantes como formativas para a docência e potencializadora de currículos mais significativos e democráticos para as classes populares. Quando nos permitimos ouvir o outro e a pensar junto a ele, nos colocamos também na posição exotópica de quem pode aprender com a experiência compartilhada.

O que os/as estudantes precisam e querem escrever? No recorte aqui apresentado trouxemos o epsódio da carta, mas tantas outras situações nos mobilizam no cotidiano da docência na EJA: navegar na rede (internet), produzir um curriculum vitae, uma placa de venda para alguma atividade comercial, uma música, uma receita etc. Ouvir atentamente as proposições de garantir espaço para desenvolver projetos que possam ir ao encontro dessas proposições pode contribuir para trazer novos sentidos para o processo ensinoaprendizagem, que articulem leitura de mundo e leitura da palavra, como nos ensina Freire.

Por outro lado, pensar a formação docente a partir da narrativa de experiências, nos permite elaborar novas compreensões sobre as práticas e o mundo da escola, construídas em processos de coautoria, que contribuem para estreitar as relações entre os discursos que definem o que a escola e os/as docentes devem ser e aquilo que de fato os/as docentes pensam e fazem acontecer no dia a dia da escola.

\section{REFERÊNCIAS}

ALVES, Nilda. Decifrando o pergaminho: o cotidiano das escolas nas lógicas das redes cotidianas. In: OLIVEIRA, Ines Barbosa; ALVES, Nilda (orgs.). Pesquisa no/do cotidiano das escolas - sobre redes de saberes. Rio de Janeiro: DP\&A, 2001.

APPLE, Michael. A luta pela democracia na educação crítica. Revista e-Curriculum, São Paulo, v. 15, n. 4, p. 894-926, out./dez. 2017. Disponível em:

$<$ https://revistas.pucsp.br/index.php/curriculum/article/view/35530>. Acesso em: 3 out. 2019.

BAKHTIN, Mikhail Mikhailovich. Estética da criação verbal. São Paulo, Martins Fontes, 2000.

BRAGANÇA, Inês. F. de S. Pesquisaformação narrativa (auto)biográfica: trajetórias e tessituras teóricometodológicas. In.: Abrahão, M. H. M. B.; Cunha, J. L. da; BÔAS, L. V. (Orgs). Pesquisa narrativa (auto)biográfica: diálogos epistêmico-metodológicos. Curitiba: CRV, 2018.

CANÁRIO, Rui. O que é a escola? Um olhar sociológico. Porto: Porto Editora, LDA, 2005.

CLANDININ, D. Jean, CONNELLY, F. Michael. Pesquisa Narrativa: experiência e história em pesquisa qualitativa. Uberlândia: Editora UFU, 2015.

COUTO, Mia. Contos: o fio das missangas. São Paulo: Companhia das Letras, 2009.

FREIRE, Paulo. Pedagogia da Autonomia. 17. ed. São Paulo: Paz e Terra, 1996.

FREIRE, Paulo. Pedagogia do oprimido. Rio de Janeiro: Paz e Terra, 2014.

GARCIA, Regina Leite. Para quem investigamos - para quem escrevemos: reflexões sobre a responsabilidade social do pesquisador. In: . et al (orgs.). Para quem pesquisamos - para quem escrevemos: o impasse dos intelectuais. 3.ed. São Paulo: Cortez, 2011. p.15-42

GARCIA, Regina Leite; ALVES, Nilda. Conversa sobre pesquisa. In: ESTEBAN, Teresa; ZACCUR, Edwiges (orgs.). Professora-pesquisadora: uma práxis em construção. 2. ed. Rio de Janeiro: DP\&A, 2002. p.97-117 
GARCIA, Regina Leite; ALVES, Nilda. Sobre a formação de professores e professoras: questões curriculares. In: LIBÂNEO, José Carlos; ALVES, Nilda. Temas de pedagogia: diálogos entre didática e currículo. São Paulo: Cortez, 2012. p. 489-510.

GERALDI, Corinta M. G. Desafios da Pesquisa no Cotidiano da/na Escola. In: GARCIA, Regina Leite; ZACCUR, Edwiges (orgs.). Cotidiano e Diferentes Saberes. Rio de Janeiro: DP\&A, 2006.

GERALDI, João Wanderley. A aula como acontecimento. São Carlos: Pedro \& João, 2015.

LARROSA, Jorge. Tremores: escritos sobre experiência. Belo Horizonte: Autêntica editora, 2014 (Coleção Educação: experiência e sentido).

LIMA, Maria Emília Caixeta de Castro; GERALDI, Corinta Maria Grisolia; GERALDI, João Wanderley. O trabalho com narrativas na investigação em Educação. Educação em Revista [online], v.31, n.1, p. 17-44, 2015. Disponível em: <https://doi.org/10.1590/0102-4698130280>. Acesso em: 28 fev. 2020.

MORAIS, Jacqueline de F. dos S.; ARAÚJO, Mairce da S. Formação Continuada Centrada na Escola: Intercambiando Experiências. Revista Teias (UERJ. Online), v.14, p. 29 - 40, 2014.

MORAIS, Jacqueline de F. dos S.; ARAÚJO, Mairce. da S. (Orgs.). Brasil-Peru: experiências educativas a partir de uma expedição pedagógica. São Carlos: Pedro \& João Editores, 2018.

NÓVOA, António. Profissão professor. Porto, Portugal: Porto editora, 1991.

NÓVOA, António (Org.). Vidas de professores. Porto, Portugal: Porto editora, 1992.

PARK, Margaret Brandini (org.). Memória, Formação de Professores, Patrimônio de Educadores, Meio Ambiente. Campinas, SP: Mercado das letras, 2003.

SANTOS, Margarida dos; et al (Orgs.). Exercícios de autoria: histórias de vida, narrativas de formação docente do/no GEFEL. Rio de Janeiro: CBJE, 2013.

SMOLKA, Ana Luiza Bustamante. A criança na fase inicial da escrita: a alfabetização como processo discursivo. 13. ed. São Paulo: Cortez, 2012.

Submetido: $13 / 06 / 2020$

Aprovado: 29/12/2021 